\title{
Radial incision and cutting combined with balloon dilation for refractory pancreaticojejunostomy anastomotic strictures
}

\section{(c) $(>)$}

\author{
Authors \\ Tadahisa Inoue, Mayu Ibusuki, Rena Kitano, Yuji Kobayashi, Tomohiko Ohashi, Yoshio Sumida, Yukiomi Nakade, \\ Kiyoaki Ito, Masashi Yoneda
}

Institution

Department of Gastroenterology, Aichi Medical University, Aichi, Japan

submitted 6.10 .2020

accepted after revision 30.12 .2020

\section{Bibliography}

Endosc Int Open 2021; 09: E578-E582

DOI 10.1055/a-1372-3628

ISSN 2364-3722

(C) 2021. The Author(s).

This is an open access article published by Thieme under the terms of the Creative Commons Attribution-NonDerivative-NonCommercial License, permitting copying and reproduction so long as the original work is given appropriate credit. Contents may not be used for commercial purposes, or adapted, remixed, transformed or built upon. (https://creativecommons.org/licenses/by-nc-nd/4.0/)

Georg Thieme Verlag KG, Rüdigerstraße 14,

70469 Stuttgart, Germany

\section{Corresponding author}

Tadahisa Inoue, MD, PhD, Department of Gastroenterology, Aichi Medical University, 1-1 Yazakokarimata, Nagakute, Aichi 480-1195, Japan

Fax: +81561633208

tinoue-tag@umin.ac.jp

\section{ABSTRACT}

Background and study aims Endoscopic balloon dilation (BD) and temporary stent placement for pancreaticojejunostomy anastomotic stricture (PJAS) achieves good shortterm outcomes; however, stricture recurrences remain frequent. We examined the feasibility of performing radial incision and cutting (RIC) combined with BD for refractory PJAS.

Patients and methods Five consecutive patients with refractory PJAS who underwent RIC with BD between 2015 and 2018 were retrospectively investigated. We evaluated the technical and clinical success, adverse event (AE), and recurrence rates associated with RIC with BD.

Results In all five patients, technical and clinical success were achieved. Pancreatic stone removal was simultaneously performed in one patient. The mean procedure time was 18 minutes (range 12-23 minutes). There were no procedure-related AEs. All patients were followed for over 2 years, with a mean follow-up period of 33 months (range 24-40 months). During the follow-up period, none of the patients developed stricture recurrence and all anastomoses remained patent.

Conclusions This is the first report of RIC with BD for the treatment of refractory PJAS, showing favorable results. This combined procedure might be a useful option for treating refractory PJAS.

\section{Introduction}

Pancreaticojejunostomy anastomotic stricture (PJAS) is an uncommon but potentially serious adverse event (AE), occurring in $1.4 \%$ to $11.4 \%$ of patients undergoing pancreaticoduodenectomy [1]. PJAS that leads to abdominal pain and/or acute pancreatitis requires treatment. Recently, endoscopic treatments, including balloon dilation (BD) and/or temporary stent placement across the stricture using balloon enteroscopy or an endoscopic ultrasound-guided approach, have been adopted as less invasive therapeutic options [2-6]. However, while good short-term outcomes are achieved in patients who undergo successful endoscopic treatment, the stricture recurrence rate is relatively high and there are cases in which complete stent removal is not possible [4-5]. Therefore, treatments that can achieve long-term resolution are needed for refractory cases.

The radial incision and cutting (RIC) method, in which the stricture is incised and the scar tissue excised, has shown promising results in the treatment of refractory anastomotic strictures including esophagogastric [7], colorectal [8], and hepaticojejunostomy strictures [9]. However, to the best of our knowledge, no study has evaluated RIC for the treatment of PJAS. Additionally, the efficacy of a combined RIC and BD approach has not been assessed and reported. This study aimed 


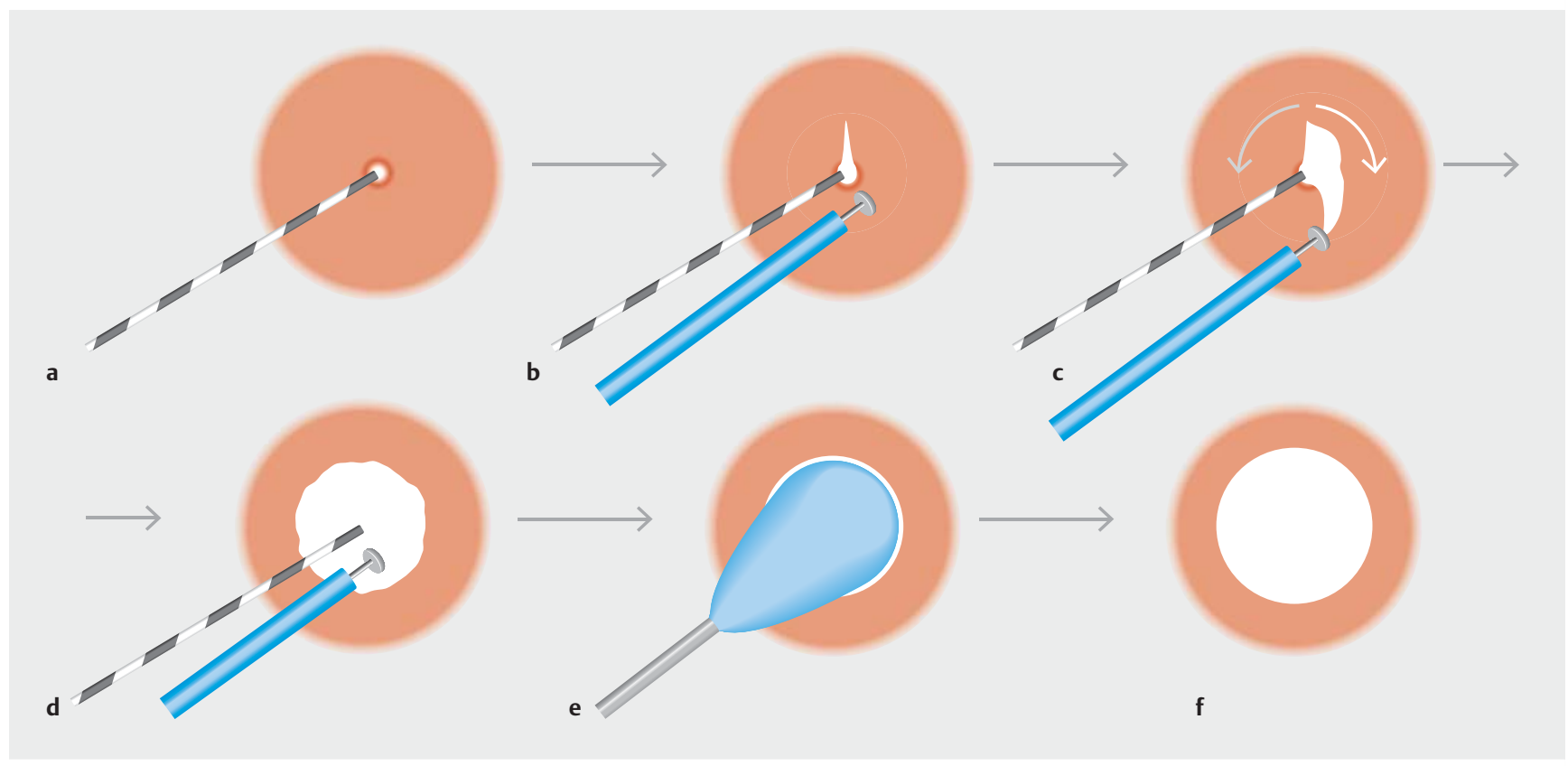

- Fig. 1 a A guidewire is inserted into the pancreatic duct across the anastomotic stricture. b One to two shallow incisions are made on the stricture site using an insulated-tip knife. $\mathbf{c}$ The scar tissue is gradually shaved in an arc starting from the incision along the lumen, using the guidewire and pancreatic duct wall as landmarks. $\mathbf{d}$ This process is repeated until the scar tissue is excised as much as possible. e, $\mathbf{f}$ Finally, balloon dilation of the stricture is performed.

to examine the feasibility of RIC combined with BD in patients with refractory PJAS.

\section{Patients and methods}

Consecutive patients with refractory PJAS who underwent RIC with BD between 2015 and 2018 were retrospectively investigated. The indications for RIC with BD in this case series were symptomatic PJAS, recurrent stricture after BD and/or temporary stent placement, and benign strictures. The institutional review board of Aichi Medical University Hospital approved this study, which was conducted in accordance with the principles of the Declaration of Helsinki (Approval number: 2020-019).

The endoscopic technique ( $\mathbf{F i g . 1}$ and $>$ Fig. 2 ) was as follows. After a short single-balloon enteroscope (SIF-H290S; Olympus Medical System, Tokyo, Japan) or a short double-balloon enteroscope (El-580BT; Fujifilm, Tokyo Japan) was inserted into the PJAS, cannulation into the pancreatic duct across the PJAS was attempted using a tapered catheter and a 0.025-inch guidewire. The tip of an insulated-tip knife (Iso-Tome; MTW Endoskopie Manufactur, Wesel, Germany), which is $1.6 \mathrm{~mm}$ in diameter and $1950 \mathrm{~mm}$ in length, was introduced into the pancreatic duct, across the PJAS, along the guidewire. If the tip could not be passed through the stricture, pre-dilation using a dilation catheter was performed. Then, one to two incisions were made at the stricture site and the scar tissue was shaved and sliced off in an arc extending from the incision along the lumen, using the guidewire and the pancreatic duct wall as landmarks. The electrosurgical unit (ESG-100; Olympus Medical Systems) was set to PulseCut mode at 20 W. Subsequently, BD of the PJAS was performed using a balloon diameter selected based on the diameter of the pancreatic duct. Stent placement or endoscopic nasopancreatic drainage after RIC with BD was not performed. All patients provided written informed consent before each procedure, and all procedures were performed by a single experienced endoscopist (T.I.).

The outcomes evaluated included technical and clinical success, adverse events, and recurrence rates. Technical success was defined as a successful procedure when the stricture was considered sufficiently dilated on fluoroscopic and endoscopic views and contrast in the pancreatic duct readily flowed into the intestine. Clinical success was defined as the resolution of perceived pancreatic-associated symptoms with no additional interventions within 2 weeks. Stricture recurrence was defined as recurrent symptoms and/or recurrent pancreatic duct dilatation on imaging studies. All patients underwent follow-up laboratory tests and imaging studies, including computed tomography and magnetic resonance cholangiopancreatography, every 3 to 6 months.

\section{Results}

Of 12 patients with PJAS who underwent endoscopic treatment, five had refractory PJAS and underwent RIC with BD. Patient characteristics are presented in $>$ Table 1 . Prior to the RIC with BD procedure, four of the patients had experienced two symptomatic stricture recurrences and one had experienced three recurrences. The mean time from the surgery involving the pancreaticojejunostomy to PJAS onset was 218 months (range 111-326 months). The mean time from the previous endoscopic treatment to current recurrence was 13 months (range 6 to 29 months). 

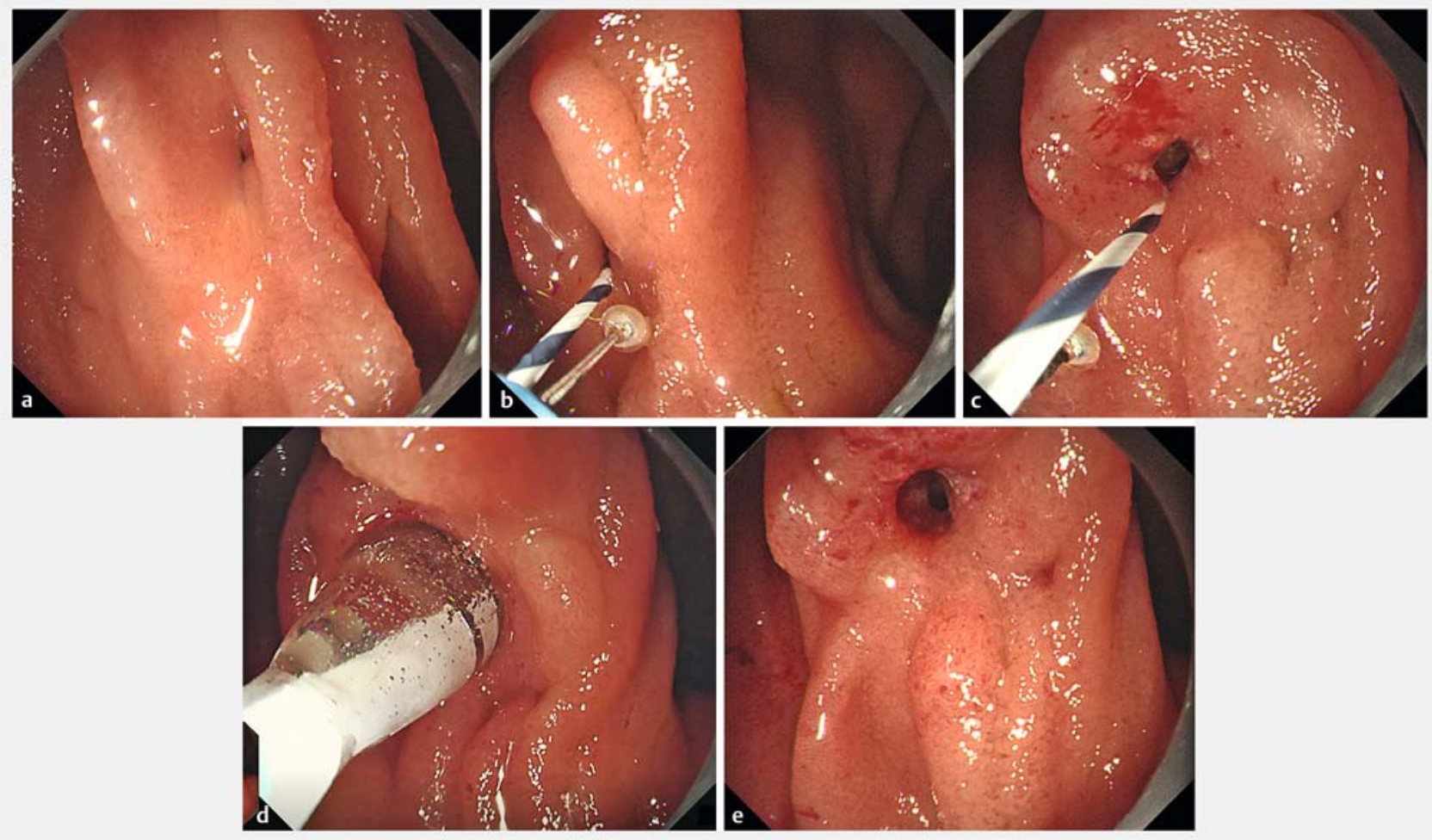

Fig. 2 a Endoscopic view showing an extremely severe, recurrent pancreaticojejunostomy stricture. b After guidewire insertion, an insulatedtip knife is inserted along the guidewire. c The stricture is incised carefully and shallowly and the scar tissue is subsequently shaved gradually. d Finally, balloon dilation of the stricture is performed. $\mathbf{e}$ The stricture improved sufficiently after the procedure.

- Table 2 presents the outcomes of RIC with BD. Technical and clinical success was achieved in all five patients. Pancreatic stone removal was simultaneously performed in one patient. The mean procedure time, from the start of the approach to the PJAS to the end of the procedure, was 18 minutes (range 12 to 23 minutes). There were no procedure-related AEs. All patients were followed for over 2 years, with a mean follow-up period of 33 months (range 24 to 40 months). During the follow-up period, the patients did not develop stricture recurrence and showed no pancreatic duct dilation on regular imaging studies ( $>$ Fig. 3 ).

\section{Discussion}

The present case series showed that the use of RIC with BD for refractory PJAS was technically feasible with good long-term outcomes and no adverse events.

Although endoscopic BD or temporary stent placement are useful as a minimally invasive treatment for PJAS, some patients only experience transient symptom resolution. The recurrence rate after endoscopic BD or stent placement was $33.3 \%$ in a recent multicenter study [5], and another study reported that most patients with PJAS did not experience any benefit from the endoscopic treatment and ultimately required surgical revision [10]. The management of PJAS is not standardized, and minimally invasive treatment methods that can achieve longterm success are needed.

RIC was first reported by Muto et al. as a novel treatment approach for refractory esophagogastric anastomotic strictures [7]. They reported a very high success rate with RIC, with 6month and 12-month patency rates significantly higher than those achieved by endoscopic BD. Thereafter, several studies reported that RIC is also promising for other anastomotic strictures including colorectal and hepaticojejunostomy [8-9]. While RIC is technically simple, excising a sufficient amount of scar tissue from the PJAS is challenging due to its narrow diameter. Merely shaving off thin layers is possible and only a small amount of the scar tissue can be removed; therefore, RIC may not be as effective as for esophagogastric anastomotic strictures. However, the existence of an anastomotic waist after BD was reported as a significant risk factor for stricture recurrence [5]. Therefore, we believed that, even if the RIC only allows for a small incision and little excision of scar tissue, it might be useful in combination with $\mathrm{BD}$, especially in patients with repeated recurrences whose scar tissue can be tough and firm. Using this combined approach, the patients in our study achieved longterm resolution of their symptoms. This result seems promising, especially considering that our patients had experiences multiple recurrences and had undergone multiple treatments before the combined RIC with BD. 
- Table 1 Baseline patient characteristics.

\begin{tabular}{|c|c|c|c|c|c|c|c|}
\hline No. & $\begin{array}{l}\text { Age } \\
\text { (years)/ } \\
\text { sex }\end{array}$ & $\begin{array}{l}\text { Indication } \\
\text { for surgery }\end{array}$ & $\begin{array}{l}\text { Specific } \\
\text { operation } \\
\text { per- } \\
\text { formed }\end{array}$ & $\begin{array}{l}\text { Time from } \\
\text { surgery to } \\
\text { symptomatic } \\
\text { PJAS onset } \\
\text { (months) }\end{array}$ & $\begin{array}{l}\text { Previous stricture treat- } \\
\text { ment }\end{array}$ & $\begin{array}{l}\text { No. of symp- } \\
\text { tomatic } \\
\text { PJAS recur- } \\
\text { rences }\end{array}$ & $\begin{array}{l}\text { Time from pre- } \\
\text { vious endoscopic } \\
\text { treatment to cur- } \\
\text { rent recurrence } \\
\text { (months) }\end{array}$ \\
\hline 1 & $72 / M$ & $\begin{array}{l}\text { Ampullary } \\
\text { cancer }\end{array}$ & PD & 302 & $\begin{array}{l}\text { BD, dilation with SSR, tem- } \\
\text { porary stent placement across } \\
\text { the PJAS }\end{array}$ & 2 & 29 \\
\hline 2 & $72 / \mathrm{M}$ & IPMN & PD & 206 & $\begin{array}{l}\text { BD, dilation with SSR, tem- } \\
\text { porary stent placement across } \\
\text { the PJAS }\end{array}$ & 3 & 7 \\
\hline 3 & $73 / \mathrm{M}$ & IPMN & PPPD & 144 & $\begin{array}{l}\text { EUS-PD, temporary stent } \\
\text { placement across the PJAS }\end{array}$ & 2 & 9 \\
\hline 4 & $72 / \mathrm{M}$ & $\begin{array}{l}\text { Bile duct } \\
\text { cancer }\end{array}$ & PD & 326 & $\begin{array}{l}\text { EUS-PD, BD, temporary stent } \\
\text { placement across the PJAS }\end{array}$ & 2 & 14 \\
\hline 5 & $55 / M$ & $\begin{array}{l}\text { Ampullary } \\
\text { cancer }\end{array}$ & PPPD & 111 & $\begin{array}{l}\text { BD, temporary stent place- } \\
\text { ment across the PJAS }\end{array}$ & 2 & 6 \\
\hline
\end{tabular}

M, male; IPMN, intraductal papillary mucinous neoplasm; PD, pancreaticoduodenectomy; PPPD, pylorus-preserving pancreaticoduodenectomy; PJAS, pancreaticojejunostomy anastomotic stricture; BD, balloon dilation; SSR, Soehendra stent retriever; EUS-PD, endoscopic ultrasound-guided pancreatic duct drainage

- Table 2 Outcomes of radial incision and cutting with balloon dilation for refractory pancreaticojejunostomy strictures.

\begin{tabular}{|c|c|c|c|c|c|c|c|c|}
\hline No. & $\begin{array}{l}\text { Technical } \\
\text { success }\end{array}$ & $\begin{array}{l}\text { Clinical } \\
\text { success }\end{array}$ & $\begin{array}{l}\text { Size of dila- } \\
\text { tion balloon }\end{array}$ & $\begin{array}{l}\text { Concurrent } \\
\text { pancreatic duct } \\
\text { stone }\end{array}$ & $\begin{array}{l}\text { Procedure time } \\
\text { (minutes) }\end{array}$ & $\begin{array}{l}\text { Adverse } \\
\text { event }\end{array}$ & $\begin{array}{l}\text { Recurrence } \\
\text { after RIC } \\
\text { with BD }\end{array}$ & $\begin{array}{l}\text { Follow-up } \\
\text { period } \\
\text { (months) }\end{array}$ \\
\hline 1 & Success & Success & $4 \mathrm{~mm}$ & None & 23 & None & None & 35 \\
\hline 2 & Success & Success & $6 \mathrm{~mm}$ & None & 17 & None & None & 31 \\
\hline 3 & Success & Success & $6 \mathrm{~mm}$ & None & 12 & None & None & 33 \\
\hline 4 & Success & Success & $8 \mathrm{~mm}$ & $\begin{array}{l}\text { Removed by balloon } \\
\text { and basket catheter }\end{array}$ & 23 & None & None & 24 \\
\hline 5 & Success & Success & $6 \mathrm{~mm}$ & None & 14 & None & None & 40 \\
\hline
\end{tabular}
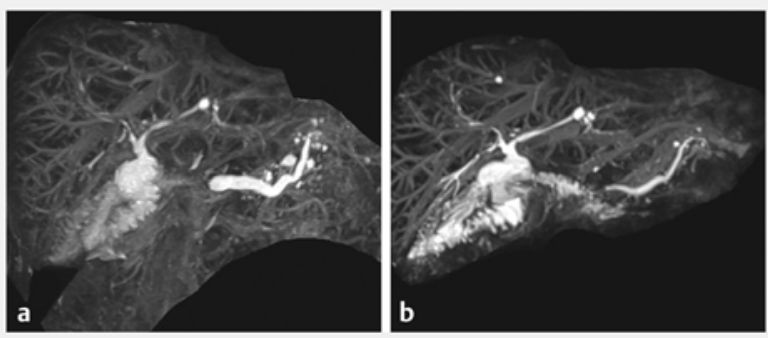

Fig. 3 Magnetic resonance cholangiopancreatography findings a before and $\mathbf{b} 2.5$ years after the radial incision and cutting with balloon dilation. The improvement in pancreatic duct dilation was maintained after the treatment.
No serious AEs associated with RIC have been reported [79]. However, a pancreaticojejunostomy is narrower and smaller than other anastomoses, and pancreatitis and perforation are a particular concern. Although no AEs occurred in the present study, this procedure should be performed with a meticulous technique and attention to detail, and should be ceased if the area that can be incised is not clear. The development of new devices for safer and easier removal of scar tissue, even from within narrow anastomoses, is expected in the future.

The present study was limited by its single-center setting, its small sample size, the involvement of a single operator, and its retrospective and nonrandomized design. Selection bias could not be avoided in this setting, and recurrence might have been underestimated because no direct endoscopic confirmation of the anastomosis after the procedure was performed. 


\section{Conclusions}

Despite the previously described limitations, this was the first study to report the use of RIC with BD for the treatment of refractory PJAS, with promising results. Additional studies are warranted to further evaluate the efficacy and safety of RIC with BD for PJAS.

\section{Competing interests}

The authors declare that they have no conflict of interest.

\section{References}

[1] Zarzavadjian Le Bian A, Cesaretti M et al. Late pancreatic anastomosis stricture following pancreaticoduodenectomy: a systematic review. J Gastrointest Surg 2018; 22: 2021-2028

[2] Chen YI, Levy M], Moreels TG et al. An international multicenter study comparing EUS-guided pancreatic duct drainage with enteroscopyassisted endoscopic retrograde pancreatography after Whipple surgery. Gastrointest Endosc 2017; 85: 170-177

[3] Kikuyama M, Itoi T, Ota Y et al. Therapeutic endoscopy for stenotic pancreatodigestive tract anastomosis after pancreatoduodenectomy (with videos). Gastrointest Endosc 2011; 73: 376-382
[4] Matsunami Y, Itoi T, Sofuni A et al. Evaluation of a new stent for EUSguided pancreatic duct drainage: long-term follow-up outcome. Endosc Int Open 2018; 6: E505-E512

[5] Sano I, Katanuma A, Kuwatani M et al. Long-term outcomes after therapeutic endoscopic retrograde cholangiopancreatography using balloon-assisted enteroscopy for anastomotic stenosis of choledochojejunostomy/pancreaticojejunostomy. J Gastroenterol Hepatol 2019; 34: 612-619

[6] Kogure H, Sato T, Nakai Y et al. Endoscopic management of pancreatic diseases in patients with surgically altered anatomy: clinical outcomes of combination of double-balloon endoscopy- and endoscopic ultrasound-guided interventions. Dig Endosc 2020: doi:10.1111/ den.13746

[7] Muto M, Ezoe Y, Yano T et al. Usefulness of endoscopic radial incision and cutting method for refractory esophagogastric anastomotic stricture (with video). Gastrointest Endosc 2012; 75: 965-972

[8] Asayama N, Nagata S, Shigita K et al. Effectiveness and safety of endoscopic radial incision and cutting for severe benign anastomotic stenosis after surgery for colorectal carcinoma: a three-case series. Endosc Int Open 2018; 6: E335-E339

[9] Inoue T, Ibusuki M, Kitano R et al. Balloon enteroscopy-assisted radial incision and cutting method for refractory hepaticojejunostomy anastomotic strictures. Endoscopy 2019; 51: 566-570

[10] Cioffi JL, McDuffie LA, Roch AM et al. Pancreaticojejunostomy stricture after pancreatoduodenectomy: outcomes after operative revision. J Gastrointest Surg 2016; 20: 293-299 